\title{
Permanent Erb's Palsy: A Lack of a Relationship with Obstetrical Risk Factors
}

\author{
Joseph G. Ouzounian, M.D., ${ }^{1}$ Lisa M. Korst, M.D., ${ }^{1}$ and Jeffrey P. Phelan, M.D. ${ }^{1}$
}

The publisher regrets an error in Table 4 of the above article in the American Journal of Perinatology, Volume 15, Number 4, p. 223. In the Levine et $\mathrm{al}^{9}$ reference, only 6 of the 36 cases of Erb's palsy reported were associated with shoulder dystocia, and 30 cases were not. The data in the original table stated that only 8 cases were not associated with shoulder dystocia. In addition, the Lipscomb et al data in the original table is listed as reference 24 , but the correct listing is reference 25 . The corrected table appears below.

\begin{tabular}{|c|c|c|c|}
\hline Authors & Reference & $\begin{array}{l}\text { Cases of } \\
\text { Erb's Palsy }(n)\end{array}$ & $\begin{array}{l}\text { Erb's Palsy Without } \\
\text { Shoulder Dystocia (n [\%]) }\end{array}$ \\
\hline Levine et al. & 9 & 36 & $30(83 \%)$ \\
\hline Lipscomb et al. & 25 & 12 & $5(42 \%)$ \\
\hline McFarland et al. & 1 & 4 & $4(100 \%)$ \\
\hline Nocon et al. & 8 & 33 & $5(15 \%)$ \\
\hline Current study & - & 63 & $4(6 \%)$ \\
\hline
\end{tabular}

Delivered by Cesarean section. 
